\title{
There Is No Advantage to Transpapillary Pancreatic Duct Stenting for the Transmural Endoscopic Drainage of Pancreatic Fluid Collections: A Meta-Analysis
}

\author{
Sunil Amin, Dennis J. Yang, Aimee L. Lucas, Susana Gonzalez and Christopher J. DiMaio \\ Division of Gastroenterology, Department of Medicine, Icahn School of Medicine at Mount Sinai, New York, NY, USA
}

Background/Aims: Options for the endoscopic management of symptomatic pancreatic fluid collections (PFCs) include transmural drainage (TM) alone, transpapillary drainage (TP) alone, or a combination of both drainage method (CD). There have been conflicting reports about the best method. This study performed a meta-analysis to determine whether CD presents an added clinical benefit over TM.

Methods: The included studies compared TM with CD and reported clinical success for both methods. A random-effects model was used to determine the pooled odds ratios (ORs) and the $95 \%$ confidence intervals (CIs) for the following outcomes: technical success, clinical success, complications, and recurrence.

Results: Nine studies involving a combined total of 604 drainage procedures-373 TMs (62\%) and $231 \mathrm{CDs}(38 \%)$-were included. CD showed no additional benefit over TM in terms of technical success (OR, 1.12; 95\% CI, 0.37-3.37; $p=0.85)$, clinical success (OR, 1.11; 95\% CI, 0.65-1.89; $p=0.70$ ), recurrence (OR, 1.49; 95\% CI, 0.53-4.21; $p=0.45$ ), or complications (OR, 1.15; 95\% CI, 0.61-2.18; $p=0.67$ ). Conclusions: Pancreatic duct (PD) stenting provides no additional clinical benefit for the TM of PFCs (particularly pseudocysts). Patients undergoing the TM of symptomatic pseudocysts may not require endoscopic retrograde pancreatography (ERP).

Clin Endosc 2017;50:388-394

Key Words: Pancreatic pseudocyst; Drainage; Endoscopy; Pancreatic fluid collection; Endoscopic retrograde pancreatography

\section{INTRODUCTION}

Pancreatic fluid collections (PFCs) may be caused by acute or chronic pancreatitis $(\mathrm{CP})$, trauma, surgery, or malignancy. Depending on the time of formation and the presence or absence of solid debris, the 2012 revised Atlanta classification defines PFCs as acute peripancreatic fluid collections, acute necrotic collections, pseudocysts, or walled-off necroses. ${ }^{1}$ In-

Received: June 25, 2016 Revised: November 14, 2016

Accepted: November 14, 2016

Correspondence: Christopher J. DiMaio

Division of Gastroenterology, Department of Medicine, Icahn School of Medicine at Mount Sinai, 1 Gustave L. Levy Place, New York, NY 10029, USA

Tel: +1-212-241-7535, Fax: +1-212-241-5440,

E-mail: christopher.dimaio@mountsinai.org

(c) This is an Open Access article distributed under the terms of the Creative Commons Attribution Non-Commercial License (http://creativecommons.org/ licenses/by-nc/3.0) which permits unrestricted non-commercial use, distribution, and reproduction in any medium, provided the original work is properly cited. dications for the drainage of PFCs include pain, gastric outlet obstruction, infection, and biliary obstruction. ${ }^{2-4}$

The endoscopic management of symptomatic PFCs, particularly pseudocysts, is safe and effective. ${ }^{5-7}$ Options for endoscopic management include transmural drainage (TM) alone, involving either a cyst-gastrostomy or cyst-duodenostomy, transpapillary drainage (TP) alone, involving an endoscopic retrograde pancreatography (ERP) procedure, or a combination of both drainage method (CD). As CD involves an ERP procedure in addition to endoscopic ultrasound (EUS), it may carry risks of additional complications such as ERP-associated pancreatitis, bleeding, and perforation beyond those associated with TM alone. There have been conflicting reports about the optimal method. Whereas in 2006, Hookey et al. found no significant difference in the treatment success rate of 116 patients who had undergone CD versus TM alone ( $91 \%$ vs. $95 \%$ ), in 2010, a subsequent study of 110 patients by Trevino et 
al. did show an advantage from CD $(97.5 \%$ vs. $80 \%$; adjusted relative risk $(\mathrm{RR})=1.14 ; 95 \%$ confidence interval $[\mathrm{CI}], 1.01-1.29$; $p=0.04),{ }^{4.8}$

The aim of this study was to perform a meta-analysis of the existing literature to determine the optimal method for the endoscopic drainage of symptomatic PFCs in terms of technical success, clinical success, recurrence, and complications.

\section{MATERIALS AND METHODS}

Our study used the meta-analysis of observational studies in epidemiology (MOOSE) guidelines, ${ }^{9}$ which provide a checklist for the reporting of meta-analyses of observational studies in epidemiology.

\section{Identification and retrieval of primary studies}

We searched PubMed, MEDLINE, and Embase for articles written in English reporting the clinical success rates of both transmural and combined drainage of PFCs. The databases were searched from their inception until February 2016, and were queried according to the following search strategy: "Pancreatic pseudocyst/therapy" (medical subject headings $[\mathrm{MeSH}])$, "PFC and drainage", "pancreatic pseudocyst and combined drainage", "pancreatic pseudocyst and transpapillary", or "pancreatic pseudocyst and transmural". The abstracts from major gastrointestinal meetings (i.e., the Digestive Diseases Week and the American College of Gastroenterology Annual Meeting) held between 2009 and 2015 were searched in order to identify any further unpublished studies that may otherwise have been missed. Articles were selected for a full text review based on their title and abstract. A further review of the references listed in the retrieved studies was performed to increase the number of potentially relevant studies.

\section{Inclusion and exclusion criteria}

The eligible studies included case series, cohort studies, or case control studies that compared the routes for the drainage of symptomatic PFCs. To be included, studies had to define and report the clinical success rates of both the TM and $\mathrm{CD}$ of PFCs. The majority of the PFCs in the included studies needed to be pseudocysts. Studies including pediatric patients, post-traumatic pseudocysts, or those whose series overlapped with that of an already included study were excluded.

\section{Study selection and data extraction}

Two authors (SA and DJY) worked independently to determine which studies met the inclusion criteria, to assess the methodology of the included studies, and to extract the demographic and outcome data. Any discrepancies were re- solved by reviewing the given study jointly. If no consensus was reached, a third author (CJD) served as an arbitrator. For each study, we extracted data on the research design, the year of publication, the country of publication, the total number of cases (TM, CD, and TP), the average age of the study participants, the average PFC size, the types of PFCs included (according to the Atlanta classification), the follow-up months, and the proportion of patients with various outcomes (technical success, clinical success, recurrence rate, and complications). In the case of studies published within the last 5 years in which the data for a particular outcome were not available, the corresponding author was contacted to check whether the missing data could be provided (2 studies)., ${ }^{8,10}$

\section{Quality assessment}

The Newcastle-Ottawa scale (NOS) was used to assess the quality of the observational studies in the analysis. ${ }^{11}$ The NOS uses a "star system" to judge studies based on three broad categories: the selection of the study groups, the comparability of the groups, and the ascertainment of the exposure or outcome of interest. A maximum of nine stars can be awarded (4 for selection, 3 for comparability, 2 for exposure), and a score of 7 or greater suggests a high-quality study. The study quality was assessed independently by two of the authors (SA and DJY), and any discrepancies were reconciled through a joint re-evaluation of the study in question.

\section{Statistical analysis}

A random-effects model was used to calculate the pooled odds ratios (ORs) and the 95\% CIs of the outcomes of interest. The random-effects model was chosen for the baseline differences in the study populations and in the outcome measurements of the included studies. The data were pooled if at least 3 studies provided data on the outcome of interest. Heterogeneity was assessed with the $I^{2}$ statistic. The publication bias was not evaluated, as our analysis included fewer than ten studies. In such cases, the powers of the Egger test and of other types of funnel plot asymmetry tests are too low to distinguish chance from real asymmetry. ${ }^{12} \mathrm{~A} p$-value $<0.05$ was considered statistically significant. All the analyses were conducted with Comprehensive Meta-Analysis, version 2 (Biostat, Englewood, NJ, USA).

\section{Outcome measures}

The primary outcome was the clinical success of TM vs. CD of PFCs. Although clinical success was defined slightly differently by each study, it generally involved either complete pseudocyst resolution at a defined time point or partial pseudocyst resolution with complete symptom resolution. The other outcomes analyzed were the technical success, 


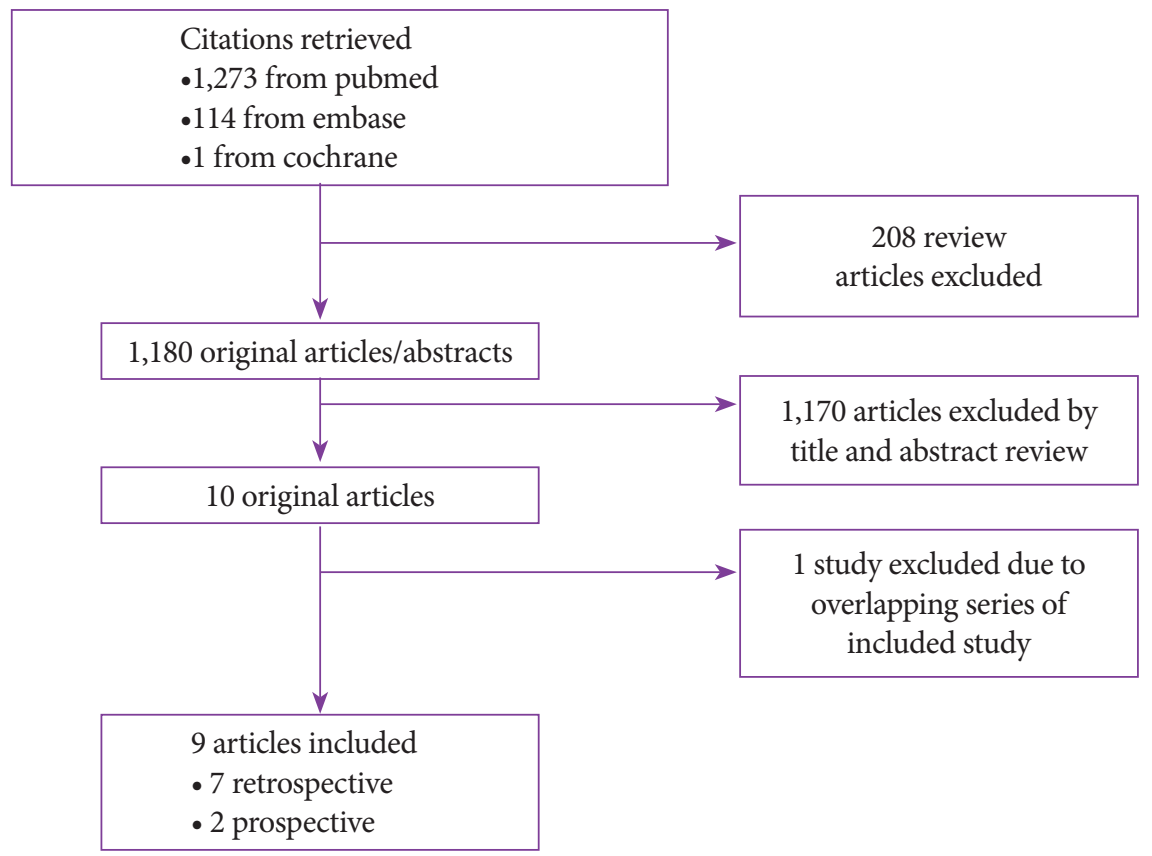

Fig. 1. Flow diagram of studies included in the meta-analysis.

Table 1. Characteristics of Studies Included in the Meta-Analysis

\begin{tabular}{|c|c|c|c|c|c|c|c|c|}
\hline Study & Type & Year & Country & Cases, $n$ & $\begin{array}{c}\text { Population } \\
\text { Age, yr }\end{array}$ & $\begin{array}{c}\text { PFC Size, } \\
\mathrm{cm}\end{array}$ & $\begin{array}{c}\text { PFC Type } \\
\text { (Atlanta } \\
\text { Classification) }\end{array}$ & $\begin{array}{c}\text { Quality } \\
\text { Score } \\
\text { (NOS) }\end{array}$ \\
\hline $\begin{array}{l}\text { Binmoeller et } \\
\text { al. }^{13}\end{array}$ & Retrospective & 1995 & Germany & $\begin{array}{c}29 \mathrm{TP} \\
20 \mathrm{TM} \\
4 \mathrm{CD}\end{array}$ & 47 (mean) & 7 (mean) & Pseudocyst & 5 \\
\hline Smits et al. ${ }^{14}$ & Retrospective & 1995 & Netherlands & $\begin{array}{c}12 \mathrm{TP} \\
17 \mathrm{TM} \\
8 \mathrm{CD}\end{array}$ & 50 (mean) & 7 (mean) & Pseudocyst & 6 \\
\hline Cahen et al. ${ }^{15}$ & Retrospective & 2005 & Netherlands & $\begin{array}{l}25 \mathrm{TP} \\
54 \mathrm{TM} \\
10 \mathrm{CD}\end{array}$ & 49 (median) & 7 (median) & Pseudocyst & 5 \\
\hline Hookey et al. ${ }^{4}$ & Retrospective & 2006 & Belgium & $\begin{array}{l}15 \mathrm{TP} \\
60 \mathrm{TM} \\
41 \mathrm{CD}\end{array}$ & $\begin{array}{r}56 \mathrm{AP}, 47 \mathrm{CP} \\
\text { (medians) }\end{array}$ & 6 (median) & $\begin{array}{l}5 \text { APFC } \\
8 \text { Necrosis } \\
94 \text { Pseudocyst } \\
9 \text { Pancreatic abscess }\end{array}$ & 5 \\
\hline Trevino et al. $^{8}$ & Retrospective & 2010 & USA & $\begin{array}{l}70 \mathrm{TM} \\
40 \mathrm{CD}\end{array}$ & 51.7 (mean) & $\begin{array}{c}\text { 10-11 (me- } \\
\text { dian) }\end{array}$ & $\begin{array}{l}67 \text { Pseudocyst } \\
17 \text { Abscess } \\
11 \text { Necrosis }\end{array}$ & 7 \\
\hline Shrode et al. ${ }^{10}$ & Retrospective & 2013 & USA & $\begin{array}{l}36 \mathrm{TP} \\
36 \mathrm{TM} \\
33 \mathrm{CD}\end{array}$ & 51.3 (mean) & NA & Pseudocyst & 8 \\
\hline Libera et al. ${ }^{16}$ & Prospective & 2000 & Brazil & $\begin{array}{c}8 \mathrm{TP} \\
12 \mathrm{TM} \\
5 \mathrm{CD}\end{array}$ & 38 (mean) & 9 (mean) & Pseudocyst & 5 \\
\hline Penn et al. ${ }^{17}$ & Prospective & 2012 & USA & $\begin{array}{c}9 \mathrm{TM} \\
11 \mathrm{CD}\end{array}$ & 57 (mean) & 13 (mean) & Pseudocyst & 6 \\
\hline Yang et al. ${ }^{18}$ & Retrospective & 2016 & USA & $\begin{array}{l}95 \mathrm{TM} \\
79 \mathrm{CD}\end{array}$ & $\begin{array}{c}52.7 \text { (mean, } \\
\text { TM), 51.4 } \\
\text { (mean, CD) }\end{array}$ & 9 (mean) & Pseudocyst & 6 \\
\hline
\end{tabular}

PFC, pancreatic fluid collection; NOS, Newcastle-Ottawa scale; TP, transpapillary drainage; TM, transmural drainage; CD, combination of both drainage method; AP, acute pancreatitis; CP, chronic pancreatitis; NA, not available; APFC, acute pancreatic fluid collection. 
Table 2 . Newcastle-Ottawa Scale Score of Included Studies

\begin{tabular}{|c|c|c|c|c|c|c|c|c|c|}
\hline Study & $\mathbf{R}$ & $S$ & $\mathbf{E}$ & ONP & $\mathrm{C}$ & OA & FL & FA & Score $(\max 9)$ \\
\hline Binmoeller et al. $(1995)^{13}$ & 1 & 0 & 1 & 1 & 0 & 0 & 1 & 1 & 5 \\
\hline Smits et al. $(1995)^{14}$ & 1 & 0 & 1 & 1 & 0 & 1 & 1 & 1 & 6 \\
\hline Cahen et al. $(2005)^{15}$ & 1 & 0 & 1 & 1 & 0 & 0 & 1 & 1 & 5 \\
\hline Hookey et al. $(2006)^{4}$ & 1 & 0 & 1 & 1 & 0 & 0 & 1 & 1 & 5 \\
\hline Trevino et al. $(2010)^{8}$ & 1 & 1 & 1 & 1 & 1 & 1 & 0 & 1 & 7 \\
\hline Shrode et al. $(2013)^{10}$ & 1 & 1 & 1 & 1 & 1 & 1 & 1 & 1 & 8 \\
\hline Libera et al. $(2000)^{16}$ & 1 & 0 & 1 & 1 & 0 & 1 & 0 & 1 & 5 \\
\hline Penn et al. $(2012)^{17}$ & 1 & 1 & 1 & 1 & 0 & 1 & 0 & 1 & 6 \\
\hline Yang et al. $(2016)^{18}$ & 1 & 0 & 1 & 1 & 1 & 1 & 0 & 1 & 6 \\
\hline
\end{tabular}

R, representativeness; S, selection; E, exposure; ONP, outcome not present; C, comparability; OA, outcome assessment; FL, follow-up length; FA, follow-up adequacy (1-year).

\section{Study name}

Statistics for each study

\begin{tabular}{|c|c|c|c|c|c|c|c|}
\hline & OR & $\begin{array}{l}\text { Lower } \\
\text { limit }\end{array}$ & $\begin{array}{l}\text { Upper } \\
\text { limit }\end{array}$ & Z-value & $p$-value & CD & TM \\
\hline Binmoeller et al. $(1995)^{13}$ & 1.976 & 0.089 & 43.626 & 0.431 & 0.666 & $4 / 4$ & $20 / 24$ \\
\hline Smits et al. $(1995)^{14}$ & 3.621 & 0.164 & 79.695 & 0.816 & 0.415 & $7 / 7$ & $14 / 17$ \\
\hline Hookey et al. (2006) & 0.487 & 0.103 & 2.301 & -0.908 & 0.364 & $37 / 41$ & $57 / 60$ \\
\hline \multirow[t]{2}{*}{ Yang et al. $(2016)^{18}$} & 2.543 & 0.259 & 24.946 & 0.801 & 0.423 & \multirow[t]{2}{*}{$78 / 79$} & \multirow[t]{2}{*}{$92 / 95$} \\
\hline & 1.112 & 0.367 & 3.365 & 0.187 & 0.851 & & \\
\hline
\end{tabular}

$I^{2}=0, p=0.52$

OR ratio and $95 \% \mathrm{Cl}$

0.01

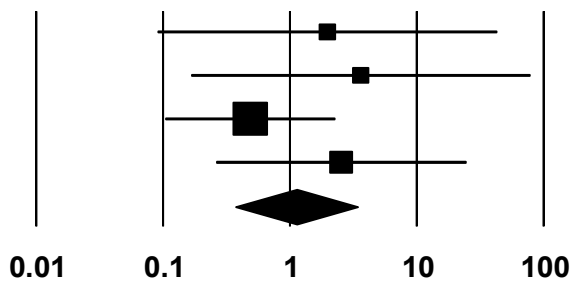

Favors TM Favors CD

Fig. 2. Technical success of transmural alone vs. combined drainage of pancreatic fluid collections (PFCs). OR, odds ratio; $\mathrm{Cl}$, confidence interval; $\mathrm{CD}$, combination of both drainage method; TM, transmural drainage.

recurrence rate, and complications. Technical success was universally defined as the successful placement of an endoprosthesis to facilitate initial drainage. The recurrence rate was influenced by the follow-up period in each study. The complications were those that occurred as a direct result of endoscopic management, including stent migration, bleeding, or post-ERP pancreatitis.

\section{RESULTS}

A total of 1,388 records were retrieved based on our search strategy (Fig. 1). After first excluding 208 review articles, the titles and abstracts of the remaining articles were reviewed to eventually select 11 articles for a full text review. After the full text review, one article was excluded as it contained a series of PFCs that overlapped with those in a previously published study. In total, 9 studies were included in the meta-analysis: 2 prospective observational studies, and 7 retrospective observational studies. $^{4,8,10,13-18}$ There have been no case control stud- ies or randomized control trials published on PFC drainage.

The study characteristics of the 9 included observational studies are given in Table 1 . The included studies contained populations from Germany, The Netherlands, Belgium, Brazil, and the United States. The mean age of the patients ranged from 38 to 57 years. The mean PFC diameter ranged from 6 to $13 \mathrm{~cm}$. The majority of the studies received a NOS score of 5 , with 2 studies scoring 7 or higher (Tables 1,2 ). Two of the studies included patients with PFCs other than pseudocysts; however, the majority of the PFCs included in these studies were pseudocysts $(81 \%$ and $71 \%) .{ }^{4,8}$ There were no data available in these studies to select only the pseudocyst cases for inclusion in the analyses.

A total of 604 drainage procedures were included in the analysis: 373 (62\%) TMs and 231 (38\%) CDs. All of the studies reported the rates of clinical success, technical success, recurrence, and complications; however, not all studies stratified these data by drainage route. Therefore, only certain studies could be included for each outcome of interest.

After applying a random-effects model to the data, the CD 
Study name

$\begin{array}{lccccccc} & \text { OR } & \begin{array}{c}\text { Lower } \\ \text { limit }\end{array} & \begin{array}{c}\text { Upper } \\ \text { limit }\end{array} & \text { Z-value } & \boldsymbol{p} \text {-value } & \text { CD } & \text { TM } \\ \text { Binmoeller et al. (1995) } & 0.692 & 0.024 & 19.946 & -0.214 & 0.830 & 4 / 4 & 19 / 20 \\ \text { Smits et al. (1995) } & 4.900 & 0.488 & 49.227 & 1.350 & 0.177 & 7 / 8 & 10 / 17 \\ \text { Libera et al. }(2000)^{16} & 2.619 & 0.106 & 64.693 & 0.588 & 0.556 & 5 / 5 & 10 / 12 \\ \text { Cahen et al. (2005) })^{15} & 4.500 & 0.528 & 38.326 & 1.376 & 0.169 & 9 / 10 & 36 / 54 \\ \text { Hookey et al. }(2006)^{4} & 0.540 & 0.167 & 1.742 & -1.032 & 0.302 & 34 / 41 & 54 / 60 \\ \text { Trevino et al. }(2010)^{8} & 9.750 & 1.231 & 77.231 & 2.157 & 0.031 & 39 / 40 & 56 / 70 \\ \text { Penn et al. }(2012)^{17} & 2.857 & 0.215 & 37.990 & 0.795 & 0.426 & 10 / 11 & 7 / 9 \\ \text { Shrode et al. }(2013)^{10} & 0.767 & 0.266 & 2.209 & -0.492 & 0.623 & 23 / 33 & 27 / 36 \\ \text { Yang et al. (2016) } & 0.720 & 0.260 & 1.991 & -0.633 & 0.527 & 24 / 39 & 20 / 29 \\ & 1.110 & 0.654 & 1.886 & 0.387 & 0.699 & & \end{array}$

$I^{2}=26.94, p=0.21$

Statistics for each study
OR ratio and $95 \% \mathrm{Cl}$

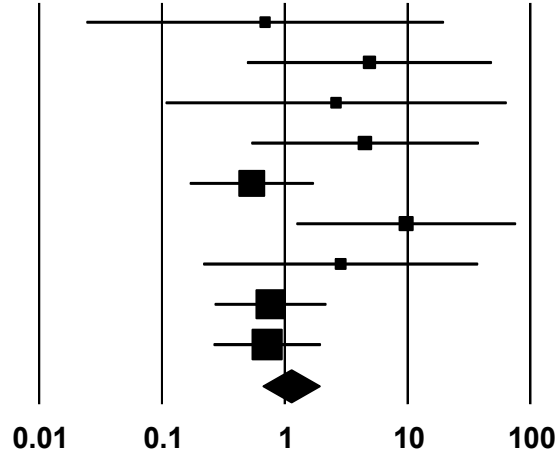

Favors TM Favors CD

Fig. 3. Clinical success of transmural alone vs. combined drainage of pancreatic fluid collections (PFCs). OR, odds ratio; $\mathrm{Cl}$, confidence interval; $\mathrm{CD}$, combination of both drainage method; TM, transmural drainage.

Study name

\begin{tabular}{|c|c|c|c|c|c|c|c|}
\hline & OR & $\begin{array}{c}\text { Lower } \\
\text { limit }\end{array}$ & $\begin{array}{l}\text { Upper } \\
\text { limit }\end{array}$ & Z-value & $p$-value & CD & TM \\
\hline Binmoeller et al. $(1995)^{13}$ & 0.231 & 0.011 & 4.961 & -0.937 & 0.349 & $0 / 4$ & $6 / 1$ \\
\hline Smits et al. $(1995)^{14}$ & 0.143 & 0.006 & 3.272 & -1.218 & 0.223 & $0 / 7$ & $3 / 10$ \\
\hline Libera et al. $(2000)^{16}$ & 0.576 & 0.020 & 16.717 & -0.321 & 0.748 & $0 / 5$ & $1 / 10$ \\
\hline Hookey et al. (2006) & 4.033 & 1.281 & 12.699 & 2.383 & 0.017 & $11 / 41$ & $5 / 60$ \\
\hline Trevino et al. $(2010)^{8}$ & 2.250 & 0.358 & 14.142 & 0.865 & 0.387 & $3 / 39$ & $2 / 56$ \\
\hline \multirow[t]{2}{*}{ Penn et al. $(2012)^{17}$} & 1.778 & 0.134 & 23.520 & 0.437 & 0.662 & \multirow[t]{2}{*}{$2 / 11$} & \multirow[t]{2}{*}{$1 / 9$} \\
\hline & 1.490 & 0.527 & 4.212 & 0.753 & 0.452 & & \\
\hline
\end{tabular}

$I^{2}=24.34, p=0.25$

Statistics for each study
OR ratio and $95 \% \mathrm{Cl}$

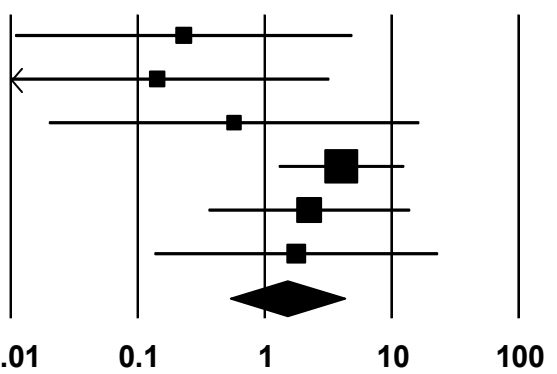

Favors CD Favors TM

Fig. 4. Recurrence rate of transmural alone vs. combined drainage of pancreatic fluid collections ( $P F C s)$. OR, odds ratio; $\mathrm{Cl}$, confidence interval; $\mathrm{CD}$, combination of both drainage method; TM, transmural drainage.

\begin{tabular}{|c|c|c|c|c|c|c|c|}
\hline \multirow[t]{2}{*}{ Study name } & \multirow[b]{2}{*}{ OR } & \multicolumn{3}{|c|}{ Statistics for each study } & \multirow[b]{2}{*}{$p$-value } & \multirow[b]{2}{*}{ CD } & \multirow[b]{2}{*}{ TM } \\
\hline & & $\begin{array}{c}\text { Lower } \\
\text { limit }\end{array}$ & $\begin{array}{c}\text { Upper } \\
\text { limit }\end{array}$ & Z-value & & & \\
\hline Libera et al. $(2000)^{16}$ & 2.000 & 0.218 & 18.332 & 0.613 & 0.540 & $2 / 5$ & $3 / 12$ \\
\hline Hookey et al. (2006) & 1.853 & 0.574 & 5.981 & 1.032 & 0.302 & $7 / 41$ & $6 / 60$ \\
\hline Penn et al. $(2012)^{17}$ & 0.350 & 0.026 & 4.654 & -0.795 & 0.426 & $1 / 11$ & $2 / 9$ \\
\hline \multirow[t]{2}{*}{ Yang et al. $(2016)^{18}$} & 0.936 & 0.399 & 2.196 & -0.152 & 0.879 & $11 / 79$ & $14 / 95$ \\
\hline & 1.150 & 0.607 & 2.176 & 0.428 & 0.668 & & \\
\hline
\end{tabular}

$$
I^{2}=0, p=0.50
$$

OR ratio and $95 \% \mathrm{Cl}$
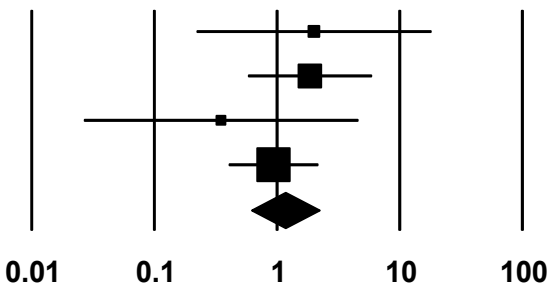

Favors CD Favors TM

Fig. 5. Complications of transmural alone vs. combined drainage of pancreatic fluid collections (PFCs). OR, odds ratio; $\mathrm{Cl}$, confidence interval; $\mathrm{CD}$, combination of both drainage method; TM, transmural drainage. 
of PFCs was not shown to be superior to TM alone for any of the four outcomes (Figs. 2-5). With regards to the technical success of the procedures, four studies were included in the analysis, with a pooled OR of 1.12 ( $95 \% \mathrm{CI}, 0.37-3.37$; $p=0.85$ ) (Fig. 2). For the primary outcome (clinical success), all 9 studies were included in the model. The resultant pooled OR of 1.11 (95\% CI, 0.65-1.89) was not statistically significant $(p=0.70)$ (Fig. 3). An $I^{2}$ value of $26.94 \%$ suggested minimal heterogeneity (Fig. 3). For the recurrence rate, 6 studies were included, with a pooled OR of 1.49 (95\% CI, 0.24-1.90; $p=0.45$ ) (Fig. 4). Finally, no difference was noted between the complications from $\mathrm{CD}$ and those from TM (OR, 1.15; 95\% CI, 0.61-2.18; $p=0.67$ ); however, relevant data were only available from four studies (Fig. 5).

\section{DISCUSSION}

The results of this meta-analysis suggested that transpapillary stenting provides no added clinical benefit for the TM of PFCs. The TM and CD methods were statistically equivalent in terms of technical success, clinical success, recurrence, and complication rates.

Our findings have several explanations and implications. First, the TM drainage of PFCs is associated with a high technical success rate, particularly when performed under EUS guidance. In the studies included in our meta-analysis, the technical success of TM drainage alone varied from $82 \%$ to $97 \%$. By contrast, the technical success rate of TP drainage, if defined as the placement of a stent across a pancreatic duct (PD) disruption/leak, is much lower. In two recent studies by the same group, bridging PD stents were successfully placed in only $42 \%-49 \%$ of patients with pseudocysts, and in $5 \%-17 \%$ of patients with walled-off necrosis. ${ }^{8,19} \mathrm{Com}$ mon reasons for failure include complete ductal disruption, gastric or duodenal obstruction, failed PD cannulation, or an altered surgical anatomy. ${ }^{8,10}$ As such, the majority of the benefits from $\mathrm{CD}$ may come from the TM component of the procedure. Even among patients in whom bridging PD stents had been successfully placed, a sub-group analysis of the above series using a multivariate logistic regression showed no additional clinical benefit from PD stenting (OR, 1.699; 95\% CI, 0.561-5144; $p=0.34$ ). ${ }^{19}$ The mechanistic explanation proposed by Hookey et al. is that pure TM may allow the cyst-enterostomy fistula to remain open longer and therefore to mature, whereas the addition of a transpapillary stent may hinder this process. ${ }^{4}$

This study had several strengths. We used a rigorous search strategy to summarize and integrate the results from 8 observational studies using a validated methodology (NOS and MOOSE). This allowed us to compensate for the small sample sizes of the individual studies and to reconcile the conflicting published results. Furthermore, minimal heterogeneity was encountered in our analysis.

The study also presented limitations. Most importantly, we were unable to control for patients with a PD leak on the pancreatogram. In the majority of the included studies, an ERP was performed prior to the attempted TM. If a PD leak was observed on the pancreatogram, the patient underwent transpapillary stent placement, with a stent placed either across the defect or into the PFC itself. Conversely, if no leak was seen on the pancreatogram, the endoscopist would proceed to TM. The decision to perform CD or TM was highly personalized, and was not a random decision. Second, due to the varying follow-up lengths, there was considerable heterogeneity in the definitions of clinical success and recurrence in the studies. As such, studies that adopted less stringent criteria may have reported higher rates of success for all procedures. Nevertheless, as these definitions were consistent within the studies, the relative ratios of success between $\mathrm{CD}$ and TM were preserved, and they were accurately reflected in the ORs. However, conclusions about specific time points cannot be inferred from our study. Third, the data were primarily compiled from retrospective observational studies, as there have been no randomized, prospective trials to evaluate the utility of combined modality drainage. Fourth, two of the included studies contained PFCs other than pseudocysts. ${ }^{4,8}$ Although the majority of the PFCs included in these studies were indeed pseudocysts ( $81 \%$ and $71 \%$, respectively), data were not available to stratify the outcomes by PFC type and drainage route. We chose not to exclude these studies, as they are large studies that are frequently cited as evidence to support divergent answers to the question at hand. Finally, some of the earlier studies included in the meta-analysis did not use EUS guidance for TM. However, several prospective studies and one meta-analysis have now reported that EUS guidance achieves higher rates of technical success without greater clinical success or more complications than non-EUS guided drainage..$^{20-23}$

In conclusion, this meta-analysis supports the notion that TP provides no additional clinical benefit over TM of PFCs, particularly pseudocysts. As a consequence of this finding, patients undergoing TM of symptomatic pseudocysts may not require an ERP procedure, and may therefore be spared the risks associated with it, notably that of post-ERP pancreatitis. Nevertheless, our study is not without limitations, and it is impossible to draw causal links based on this analysis. Future prospective studies should place an emphasis on randomization to ensure that the patients undergoing TM and $\mathrm{CD}$ have similar baseline characteristics, particularly in 
terms of the presence or absence of pancreatic ductal disruption.

\section{Conflicts of Interest}

The authors have no financial conflicts of interest.

\section{Conference Presentation}

This work was presented as an oral presentation at Digestive Disease Week (DDW) 2015.

\section{REFERENCES}

1. Banks PA, Bollen TL, Dervenis C, et al. Classification of acute pancreatitis--2012: revision of the Atlanta classification and definitions by international consensus. Gut 2013;62:102-111.

2. Cheruvu CV, Clarke MG, Prentice M, Eyre-Brook IA. Conservative treatment as an option in the management of pancreatic pseudocyst. Ann R Coll Surg Engl 2003;85:313-316.

3. Soliani P, Franzini C, Ziegler S, et al. Pancreatic pseudocysts following acute pancreatitis: risk factors influencing therapeutic outcomes. JOP 2004;5:338-347.

4. Hookey LC, Debroux S, Delhaye M, Arvanitakis M, Le Moine O, Devière J. Endoscopic drainage of pancreatic-fluid collections in 116 patients: a comparison of etiologies, drainage techniques, and outcomes. Gastrointest Endosc 2006;63:635-643.

5. Larsen M, Kozarek R. Management of pancreatic ductal leaks and fistulae. J Gastroenterol Hepatol 2014;29:1360-1370.

6. Varadarajulu S, Bang JY, Sutton BS, Trevino JM, Christein JD, Wilcox CM. Equal efficacy of endoscopic and surgical cystogastrostomy for pancreatic pseudocyst drainage in a randomized trial. Gastroenterology 2013;145:583-590.e1

7. Varadarajulu S, Lopes TL, Wilcox CM, Drelichman ER, Kilgore ML, Christein JD. EUS versus surgical cyst-gastrostomy for management of pancreatic pseudocysts. Gastrointest Endosc 2008;68:649-655.

8. Trevino JM, Tamhane A, Varadarajulu S. Successful stenting in ductal disruption favorably impacts treatment outcomes in patients undergoing transmural drainage of peripancreatic fluid collections. J Gastroenterol Hepatol 2010;25:526-531.

9. Stroup DF, Berlin JA, Morton SC, et al. Meta-analysis of observational studies in epidemiology: a proposal for reporting. Meta-analysis of observational studies in epidemiology (MOOSE) group. JAMA 2000;283:2008-2012.

10. Shrode CW, Macdonough P, Gaidhane M, et al. Multimodality endoscopic treatment of pancreatic duct disruption with stenting and pseudocyst drainage: how efficacious is it? Dig Liver Dis 2013;45:129-
133.

11. Wells GA, Shea B, O'Connell D, et al. The Newcastle-Ottawa scale (NOS) for assessing the quality of non-randomized studies in meta-analyses [Internet]. Ottawa: Ottawa Hospital Research Institute; c2014 [cited 2015 Jun 11]. Available from: http://www.ohri.ca/programs/clinical_epidemiology/oxford.asp.

12. Sterne JA, Sutton AJ, Ioannidis JP, et al. Recommendations for examining and interpreting funnel plot asymmetry in meta-analyses of randomised controlled trials. BMJ 2011;343:d4002.

13. Binmoeller KF, Seifert H, Walter A, Soehendra N. Transpapillary and transmural drainage of pancreatic pseudocysts. Gastrointest Endosc 1995;42:219-224.

14. Smits ME, Rauws EA, Tytgat GN, Huibregtse K. The efficacy of endoscopic treatment of pancreatic pseudocysts. Gastrointest Endosc 1995;42:202-207.

15. Cahen D, Rauws E, Fockens P, Weverling G, Huibregtse K, Bruno M. Endoscopic drainage of pancreatic pseudocysts: long-term outcome and procedural factors associated with safe and successful treatment. Endoscopy 2005;37:977-983.

16. Libera ED, Siqueira ES, Morais M, et al. Pancreatic pseudocysts transpapillary and transmural drainage. HPB Surg 2000;11:333-338.

17. Penn DE, Draganov PV, Wagh MS, Forsmark CE, Gupte AR, Chauhan SS. Prospective evaluation of the use of fully covered self-expanding metal stents for EUS-guided transmural drainage of pancreatic pseudocysts. Gastrointest Endosc 2012;76:679-684.

18. Yang D, Amin S, Gonzalez S, et al. Transpapillary drainage has no added benefit on treatment outcomes in patients undergoing EUS-guided transmural drainage of pancreatic pseudocysts: a large multicenter study. Gastrointest Endosc 2016;83:720-729.

19. Varadarajulu S, Bang JY, Phadnis MA, Christein JD, Wilcox CM. Endoscopic transmural drainage of peripancreatic fluid collections: outcomes and predictors of treatment success in 211 consecutive patients. J Gastrointest Surg 2011;15:2080-2088.

20. Park DH, Lee SS, Moon SH, et al. Endoscopic ultrasound-guided versus conventional transmural drainage for pancreatic pseudocysts: a prospective randomized trial. Endoscopy 2009;41:842-848

21. Kahaleh M, Shami VM, Conaway MR, et al. Endoscopic ultrasound drainage of pancreatic pseudocyst: a prospective comparison with conventional endoscopic drainage. Endoscopy 2006;38:355-359.

22. Varadarajulu S, Christein JD, Tamhane A, Drelichman ER, Wilcox CM. Prospective randomized trial comparing EUS and EGD for transmural drainage of pancreatic pseudocysts (with videos). Gastrointest Endosc 2008;68:1102-1111.

23. Panamonta N, Ngamruengphong S, Kijsirichareanchai K, Nugent K, Rakvit A. Endoscopic ultrasound-guided versus conventional transmural techniques have comparable treatment outcomes in draining pancreatic pseudocysts. Eur J Gastroenterol Hepatol 2012;24:1355-1362. 